\title{
DIVERSIDAD DE ICTIOPLANCTON EN LOS RÍOS CURARAY, ARABELA Y NAPO (AMAZONIA PERUANA)
}

Carmen Rosa GARCÍA-DÁVILA ${ }^{1,4}$, Diana CASTRO RUIZ ${ }^{1,4}$, Homero SÁNCHEZ RIBEIRO ${ }^{2,4}$, Rosa ISMIÑO ORBE ${ }^{2,4}$, Dixner RENGIFO TRIGOSO ${ }^{1,4}$, Aurea GARCÍA VASQUEZ ${ }^{2,4}$, Salvador TELLO MARTIN $^{2,4}$, Werner CHOTA-MACUYAMA ${ }^{2,4}$, Fabrice DUPONCHELLI ${ }^{3,4}$, Jean François RENNO ${ }^{3,4}$

1 Laboratorio de Biología y Genética Molecular - LBGM, Instituto de Investigaciones de la Amazonía Peruana - IIAP. Programa para el Uso y Conservación del Agua y sus Recursos - AQUAREC. Carretera Iquitos -Nauta km 2,5, Iquitos, Perú.Cdavila19@yahoo.com

2 Programa para el Uso y Conservación del Agua y sus Recursos - AQUAREC, Instituto de Investigaciones de la Amazonía Peruana-IIAP. Carretera Iquitos -Nauta km 2.5, Iquitos, Perú.

3 Institut de Recherche pour le Développement (IRD). Montpellier, France.

4 Laboratoire Mixte International - Evolution et Domestication de l'Ichtyofaune Amazonienne (LMI-EDIA).

\section{RESUMEN}

Se analizó la diversidad específica de 689 larvas de peces colectadas en los periodos de creciente y vaciante del 2012 en siete estaciones de colecta en las cuencas del Napo, Arabela y Curaray. Las larvas fueron identificadas mediante secuenciamiento nucleotídico del gen Citocromo oxidasa sub unidad I (COI). Los resultados muestran diferencias en la abundancia de larvas entre los periodos hidrológicos ( 165 y 524 larvas, respectivamente, en creciente y vaciante) y entre cuencas. Se identificaron un total de 11 especies. En la época de creciente, predominaron las larvas de la especie Pimelodus blochii cunchi (142=86,06\% de la captura), en tanto que en la época de vaciante predominaron las larvas de la especie Hydrolicus scomberoides huapeta (404=77,10\% de la captura). La estación con mayor número de larvas en la época de creciente fue Shapajal río Curaray (137 larvas - 83,03\%), mientras que en la época de vaciante fue Boca del Curaray - río Napo (340 larvas $-64,89 \%)$. En el río Arabela no fue registrada la presencia de larvas en ninguno de los dos periodos hidrológicos evaluados. Larvas de bagres como el dorado Brachyplatystoma rosseauxii, el saltón $B$. filamentosum y tabla barba B. platynemum, fueron encontradas en los ríos Curaray y Napo, confirmando la importancia de los ríos de aguas blancas en el mantenimiento del ciclo de vida de estos grandes bagres.

PALABRAS CLAVE: peces amazónicos, larvas, Amazonía peruana, barcoding, Citrocomo oxidasa, COI

\section{EVALUATIÓN OF ICHTHYOPLANKTON DIVERSITY IN HIGH WATER AND LOW WATER IN THE CURARAY, ARABELA AND NAPO RIVERS (PERUVIAN AMAZON).}

\section{ABSTRACT}

We analyzed the species diversity of 689 fish larvae collected during periods of high and low waters of 2012 in seven stations of the Napo, Arabela and Curaray rivers. The larvae were identified by nucleotide sequencing of the gene Cytochrome Oxidase sub unit I (COI). The results show differences in larval abundance between the two hydrological periods (165 and 524 larvae in growing and dry season, respectively) and between basins, suggesting differential breeding periods. A total of 11 species were identified among 689 larvae analyzed, in high water the greater number of larvae were identified as cunchi Pimelodus blochii ( $142=86.06 \%$ of the catch ), while in low water the larvae of huapeta Hydrolicus scomberoides dominated ( $404=77.10 \%$ of the catch). During the high water season, the station with the highest number of larvae was Shapajal (Curaray river) with 137 larvae $(83.03 \%)$, whereas it was Boca Curaray (Napo river) with 340 larvae $(64.89 \%$ ) in the dry season. Not a single larvae was collected in the Arabela River in either hydrological periods. Catfish larvae like the dorado Brachyplatystoma rosseauxii, saltón B. filamentosum and tabla baba B. platynemum; were found in the Napo and Curaray rivers, confirming the importance of the white water rivers in the maintenance of the life cycle of these large catfish.

KEYWORDS: Fish larvae, Peruvian Amazon, barcoding, Citocromo oxidasa, COI 


\section{INTRODUCCIÓN}

La región amazónica comprende cerca de un tercio de toda América del Sur (6 $\left.112000 \mathrm{~km}^{2}\right)$. Alberga las mayores cuencas hidrográficas del mundo, y posee la mayor diversidad de especies de peces de agua dulce (Barthem y Goulding, 1997; Reis et al., 2004; Barthem y Goulding, 2007). La Amazonía peruana es parte de este gran complejo, ocupando una extensión territorial de aproximadamente dos tercios $\left(747282 \mathrm{~km}^{2}\right)$ de la superficie del Perú. Actualmente, estos ecosistemas están sujetos no solo a los efectos del cambio climático global (cambios en los periodos de precipitación, de temperatura y régimen hidrológico), sino también a los efectos derivados de las actividades sociales y económicas del hombre. Estos factores no solo alteran la composición química de las aguas, sino también el volumen de las mismas y por ende influencian la diversidad y abundancia de las especies que en ellas habitan (Barthem y Goulding, 1997; Galvis et al., 2006; García-Vásquez, 2009; Ortega et al., 2010; Mojica et al., 2012). El monitoreo de las condiciones físicas, químicas y biológicas de los ecosistemas, así como de la diversidad y abundancia de sus organismos, permite conocer las tendencias de estos ecosistemas a través del tiempo. Estas informaciones constituyen una herramienta importante para establecer la línea base para futuros planes de contingencia en estas cuencas hidrográficas (Kurt, et al., 2001; Habit et al., 2003).

El conocimiento de las áreas y la dinámica de reproducción de los peces es una herramienta muy importante para la formulación de políticas de protección y manejo efectivas para la bioconservación de este recurso. El principal limitante para realizar el monitoreo reproductivo de poblaciones naturales de peces a través de la dinámica de ocurrencia de sus larvas, es la gran semejanza morfológica que presentan las larvas de algunos grupos de peces, como por ejemplo los bagres, que dificulta distinguirlos a nivel de género y especie (García-Dávila et al., 2009; Carvalho y Araujo-Lima, 2004). La identificación de las larvas está basada en el análisis de caracteres morfológicos, como el conteo de miómeros o somitos, patrones de pigmentación y caracteres morfométricos como longitud total, longitud estándar, diámetro del ojo, etc. (Araujo-Lima y Donald, 1988; Nakatani et al., 2001; Carvalho y Araujo-Lima, 2004; Leite et al., 2006; Leite et al., 2007). En los últimos años el uso de secuencias de DNA (Barcoding) se viene empleando consistentemente en la identificación molecular de especies de peces, sus subproductos (filete fresco, seco-salado, fresco- saldado, etc.) e inclusive, sus larvas (Hubert et al., 2008; Steinker et al., 2009; García-Dávila et al., 2009; Ardura et al., 2010; Asgharian et al., 2011; Zhang y Hanner, 2011; Wong et al., 2011). Con el uso de las secuencias del gen Citocromo oxidasa sub unidad I (COI), como región estándar para el DNA Barcoding, se puede obtener información de la identidad especifica de estos seres vivos en forma rápida, precisa y automatizada (Hebert et al. 2004 a,b; Hubert et al., 2008; Aquilino et al., 2011; Lakra et al., 2011). El objetivo del presente estudio fue utilizar el secuenciamiento nucleotídico del gen Citocromo oxidadasa sub unidad I (COI) como herramienta para identificar molecularmente las larvas de peces colectados en siete localidades de los ríos Arabela, Curaray y Napo.

\section{MATERIALES Y MÉTODOS}

\section{Colecta de larvas}

Las larvas fueron colectadas en siete estaciones de muestreo de la cuenca del río Napo (Figura 1), dos en el río Arabela (Panguana $=\mathrm{A} 1$, Flor de Coco $=$ $\mathrm{A} 2$ ), tres en el río Curaray (Arica $=\mathrm{C} 1$, Urbina $=\mathrm{C} 2$, Shapajal $=\mathrm{C} 3$ ) y dos en la cuenca media del río Napo [500 metros aguas arriba y 500 aguas debajo del delta del río Curaray (Nuevo Defensor $=$ N1, Boca del Curaray $=\mathrm{N} 2$ )].

Se realizaron dos monitoreos de ictioplancton en cada una de las estaciones de colecta, uno durante el periodo hidrológico de creciente (mayo) y otro durante el periodo hidrológico de vaciante (octubre) del año 2012. En cada monitoreo se realizaron cinco lances de 15 minutos cada uno por estación de colecta. Las redes fueron acondicionadas siguiendo la metodología planteada en los estudios realizados por Leite, (2007) y García-Dávila et al., (2009). La determinación equitativa de los tres estratos de muestreo (superficial, medio y fondo) fue realizada teniendo en cuenta la profundidad del río y teniendo en cuenta que la última red debía estar como mínimo a tres metros del lecho del río. Las larvas fueron capturadas con redes cónicas para ictiopláncton tipo Tucker Trawl, con una longitud de 2 metros y una superficie de ingreso (boca) de $0,25 \mathrm{~m}^{2}(0,45 \mathrm{X} 0,55)$ y $0,5 \mathrm{~cm}$ de malla, con un frasco colector de un litro de capacidad en su extremo distal. Se utilizó un bote de madera de siete metros de largo y dos de ancho.

Las redes fueron fijadas en un cabo en cuyo extremo estaba asegurada un ancla de $20 \mathrm{~kg}$. Las redes sumergidas viajaban a contra corriente con ayuda de un motor fuera de borda de $15 \mathrm{HP}$ por espacio de 15 minutos (Figura 2). 


\section{Análisis de laboratorio}

\section{Extracción amplificación y secuenciamiento nucleotídico de $A D N$}

La extracción fue realizada mediante el método CTAB (Doyle y Doyle, 1987) a partir de tejido muscular de los adultos y del total de la larva, a la que se le extrajo los intestinos para evitar DNA exógeno (restos de Fito o Zooplancton del alimento). El gen citocromo oxidasa sub unidad I (COI, $576 \mathrm{pb}$ ) fue amplificado utilizando los primeros Fish F1 5'-TCA ACC AAC CAC AAA GAC ATT GGC AC-3' y Fish R1 5'-TAG ACT TCT GGG TGG CCA AAG AAT CA-3' (Hubert et al., 2008). La amplificación vía PCR fue realizada en un volumen final de $15 \mu 1$ conteniendo 6,78 ul de agua ultra pura, 3 ul de $5 \mathrm{x}$ PCR tampón, 0,9 ul de MgCl2 (25 mM), 0,6 ul de cada primer $(10 \mathrm{uM}), 1,5 \mathrm{ul}$ del mix de dNTP (2 $\mathrm{mM}), 0,12 \mathrm{ul}(5 \mathrm{U} / \mathrm{ul})$ de Taq ADN polimerasa (Promega), y 1,5 ul (100 ng/ul) de ADN molde. Las condiciones de PCR fueron de $94^{\circ} \mathrm{C}$ durante $2 \mathrm{~min}$, 35 ciclos de $94^{\circ} \mathrm{C}$ durante $30 \mathrm{~s}, 54^{\circ} \mathrm{C} 40 \mathrm{~s}$, y $72^{\circ} \mathrm{C}$ durante $1 \mathrm{~min}$, con una extensión final a $72^{\circ} \mathrm{C}$ durante 10 minutos. Los productos de PCR del gen COI fueron secuenciados utilizando los mismos primer de la amplificación en un analizador genético 3130XL (Applied Biosystems).

\section{Determinación de identidad genética de las larvas}

Para cada larva fue editada una secuencia consenso (unión de secuencias Forward y Reverse). Las secuencias editadas de las larvas fueron alineadas en una matriz de alineamiento múltiple conteniendo las secuencias de 180 adultos perfectamente identificados a nivel morfológico, con ayuda del programa de alineamiento múltiple ClustalW (Thompson et al., 1994) que está dentro del software BioEdit v.7.0.9. (Hall, 1999). Para la determinación de la identidad de las larvas se estimó primeramente el modelo de evolución molecular en base a la matriz de secuencias con ayuda del software R (Paradis et al., 2004).

La identidad molecular de las larvas fue determinada a través de la relación filogenética de la secuencia de la larva con las secuencias de los bagres adultos en un árbol filogenético (Figura 3), El árbol fue construido bajo el método de vecino próximo (Neighbor-Joining - NJ) utilizando el software MEGA4.0 (Tamura et al., 2007).

\section{RESULTADOS}

\section{Abundancia de larvas en las estaciones de muestreo}

Se colectaron un total de 689 larvas en las siete estaciones de muestreo (tabla 1), en los dos periodos hidrográficos evaluados (165 en creciente y 524 en vaciante). La diferencia en la abundancia de ictioplancton entre algunas de las diferentes estaciones de colecta fue muy grande, presentando algunas estaciones una abundancia considerable de larvas (Shapajal $=137$, Boca del Curaray $=340$ ), en tanto que en otras este recurso estuvo ausente (Panguana A2 y flor de Coco A1, cuenca del río Arabela).

Se observó también la diferencia en la abundancia de larvas capturadas en las estaciones de muestreo entre los periodo hidrológicos de vaciante y creciente. En creciente la mayor cantidad de larvas fue capturada en la estación del Shapajal C3 (137, $83,03 \%$ de las larvas capturadas en el periodo), en tanto que en vaciante la mayor abundancia fue registrada en la estación Boca del Curaray N2, con 340 larvas, que representan $63,20 \%$ del total colectado en el periodo de aguas bajas (Tabla 1).

\section{Composición y abundancia específica de las larvas}

El análisis de las secuencias nucleotídicas, muestra que las 689 larvas analizadas están agrupadas en un total de 11 especies de peces (Tabla 2). La composición específica de las larvas fue diferente en los periodos de creciente y vaciante. En creciente se encontraron larvas de nueve especies de bagres, perteneciendo el mayor volumen de las larvas a la especie Pimelodus blochii, comúnmente conocido como cunchi $(142=86,06 \%)$. Este pequeño bagre tuvo una presencia muy reducida en el periodo de vaciante ( 4 larvas $=0,79 \%$ ).

En los cauces principales de los ríos Napo y Curaray, durante el periodo de vaciante, se identificaron, entre las larvas analizadas, un total de siete especies de peces. La especie que presentó mayor número de larvas fue Hydrolicus scomberoides ( $77,10 \%$ de la captura), Characiforme comúnmente conocido como huapeta. Si bien, durante este periodo las larvas de siluriformes representaron solo el $23 \%$ de la colecta, el mayor porcentaje de las encontradas, pertenecían a especies de bagres de mediano y gran porte como el dorado tabla barba Brachyplatystoma platynemum, Brachyplatystoma rousseauxii y saltón Brachyplatystoma filamentosum $(10,32 \%, 4,0 \% \mathrm{y}$ $3,82 \%$, respectivamente).

Solo cuatro (tabla baba $B$. platynemum, dorado $B$. rousseauxii, saltón $B$. filamentosus y cunchi $P$. blochii) de las 11 especies de larvas identificadas estuvieron presentes en ambos periodos hidrológicos, en tanto que las especies restantes estuvieron presentes únicamente en el periodo de creciente o de vaciante (Tabla 2, Figura 4). 
De las 11 especies de peces identificados en las 689 larvas estudiadas, H. scomberoides estuvó presente en el mayor número de estaciones en el periodo de vaciante (en cinco de las siete estaciones). En creciente no se observó esta marcada predominancia de las larvas de una especie sobre las otras (Tabla 2). En cuanto a la composición de las larvas, las estaciones del río Curaray fueron las que presentaron mayor número de especies (siete especies en cada periodo hidrológico).

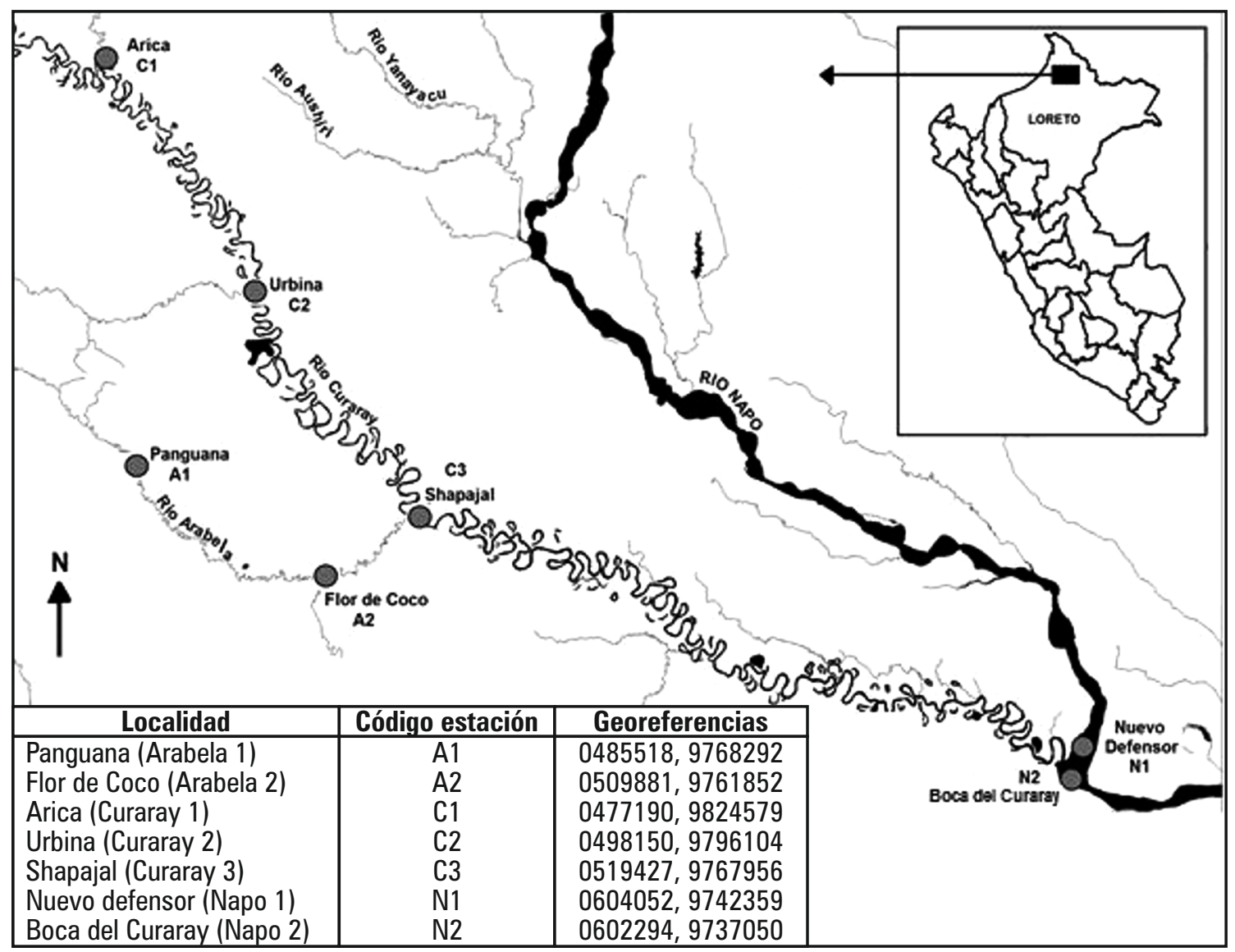

Figura 1. Área de estudio mostrando la ubicación, códigos y georeferencias de las localidades de colecta de larvas en vaciante y creciente del 2012 en los ríos Arabela, Curaray y Napo. 


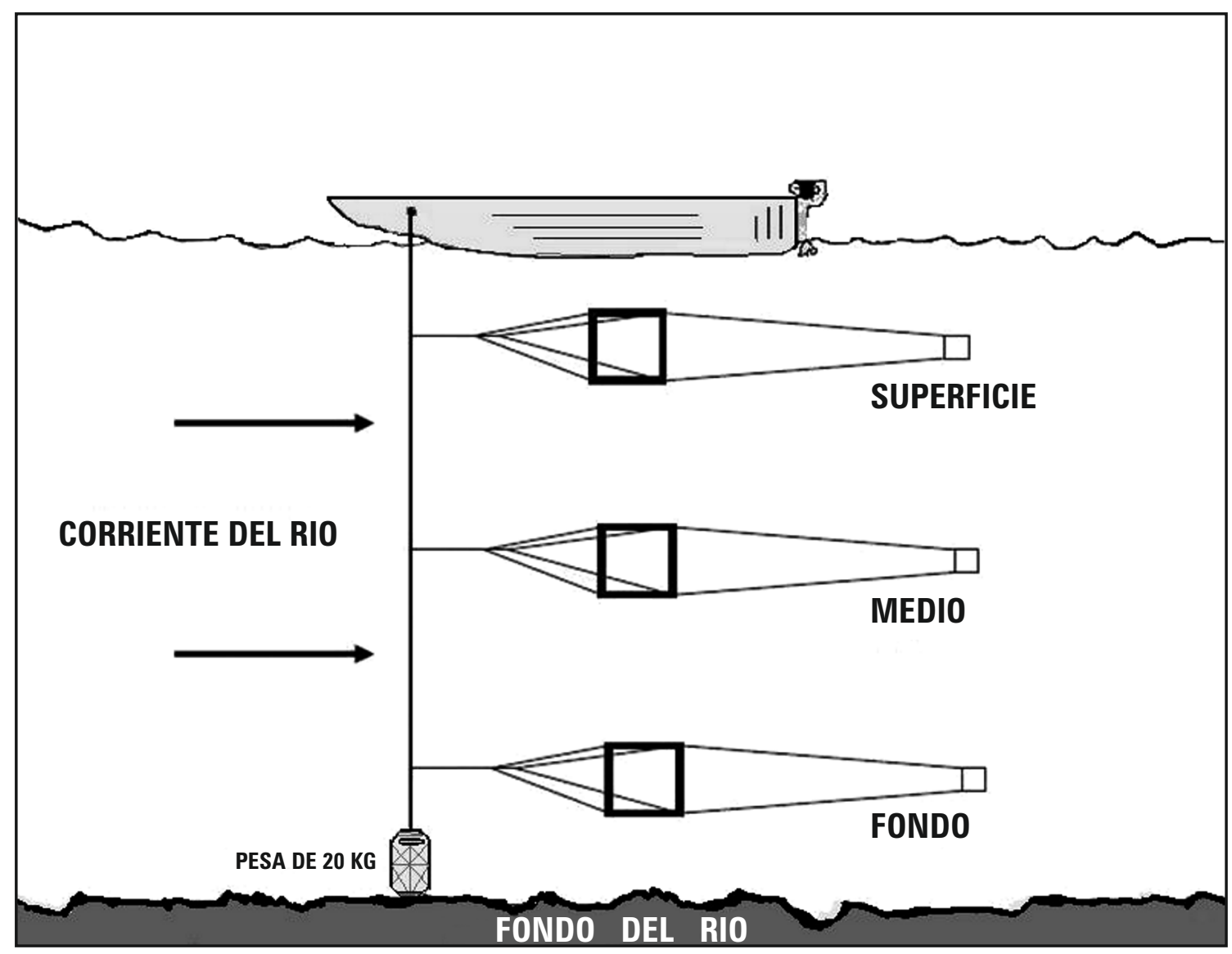

Figura 2. Esquema mostrando la colecta de larvas de peces mediante redes móviles a contra corriente en el cauce central del río. 


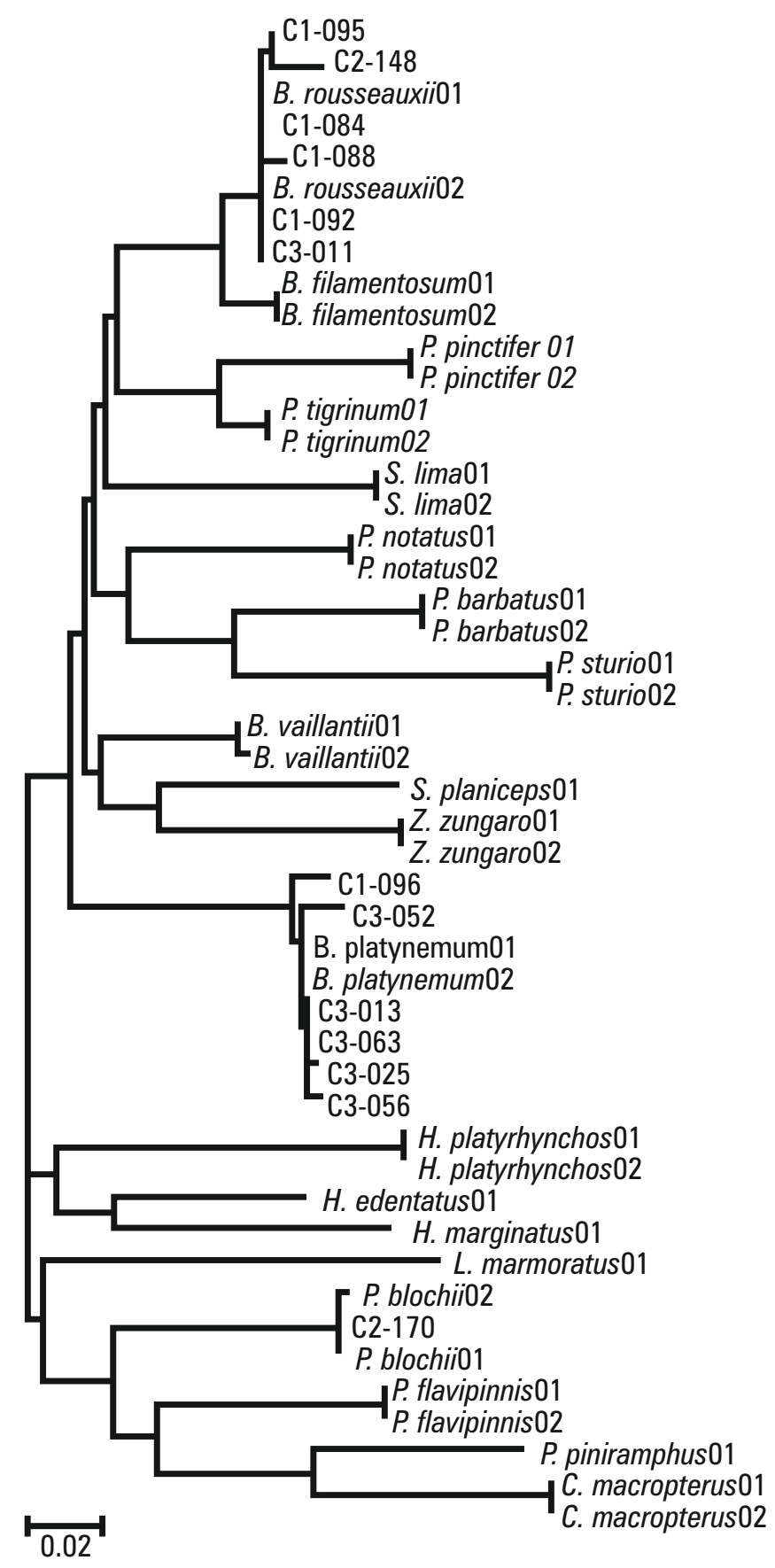

Figura 3. Árbol consenso de Neighbor-Joining (NJ), mostrando las relaciones entre las larvas y los especímenes adultos. 
Tabla 1. Numero de larvas colectadas en las siete estaciones en el periodo de creciente y vaciante del 2012 en los ríos Arabela, Curaray y Napo.

\begin{tabular}{lccc|c|c}
\hline \multirow{2}{*}{ Estaciones } & \multicolumn{2}{c|}{ Creciente } & \multicolumn{2}{c}{ Vaciante } \\
\cline { 2 - 5 } & Numero & $\%$ & Numero & $\%$ \\
\hline Panguana(A1) & 0 & 0 & 0 & 0 \\
Flor de coco (A2) & 0 & 0 & 0 & 0 \\
N. Defensor (N1) & 2 & 1,21 & 22 & 1,21 \\
Boca Curaray (N2) & 12 & 7,27 & 340 & 7,27 \\
Arica (C1) & 1 & 0,61 & 61 & 0,61 \\
Urbina (C2) & 13 & 7,88 & 51 & 7,88 \\
Shapajal (C3) & 137 & 83,03 & 50 & 83,03 \\
\hline Total & 165 & $100 \%$ & 524 & $100 \%$ \\
\hline
\end{tabular}

Tabla 2. Abundancia y composición de larvas por estaciones de muestreo en los periodos hidrobiológicos de creciente y vaciante del 2012 en los ríos Curaray y Napo.

\begin{tabular}{|c|c|c|c|c|c|c|c|c|c|c|c|c|c|c|c|c|c|c|c|}
\hline \multirow{2}{*}{ Especies } & \multicolumn{9}{|c|}{ Creciente } & \multicolumn{9}{|c|}{ Vaciante } & \multirow{2}{*}{ Tota } \\
\hline & A1 & A2 & C1 & C2 & C3 & N1 & N2 & \begin{tabular}{|l|}
$N^{\circ}$ \\
Total \\
\end{tabular} & $\%$ & A1 & A2 & C1 & C2 & C3 & N1 & N2 & \begin{tabular}{|l|l|}
$N^{\circ}$ \\
Total \\
\end{tabular} & $\%$ & \\
\hline P. blochii & & & & 8 & 123 & & 11 & 142 & 86,06 & & & & 4 & & & & 4 & 0,76 & 146 \\
\hline B. filamentosum & & & & & 4 & & 1 & 5 & 3,03 & & & & 6 & & 14 & & 20 & 3,82 & 25 \\
\hline B. platynemum & & & & & 2 & & & 2 & 1,20 & & & 23 & 8 & 23 & & & 54 & 10,32 & 56 \\
\hline B. rousseauxii & & & & 3 & 2 & 1 & & 6 & 3,64 & & & 4 & 13 & 4 & & & 21 & 4,00 & 27 \\
\hline L. marmoratus & & & & & 5 & 1 & & 6 & 3,64 & & & & & & & & 0 & 0,00 & 6 \\
\hline P. barbatus & & & 1 & & & & & 1 & 0,62 & & & & & & & & 0 & 0,00 & 1 \\
\hline S. lima & & & & 2 & & & & 2 & 1,20 & & & & & & & & 0 & 0,00 & 2 \\
\hline P. flavipinnis & & & & & 1 & & & 1 & 0,61 & & & & & & & & 0 & 0,00 & 1 \\
\hline H. marginatus & & & & & & & & 0 & 0,00 & & & 5 & 1 & 5 & & & 11 & 2,10 & 11 \\
\hline P. notatus & & & & & & & & 0 & 0,00 & & & 2 & & 5 & & 3 & 10 & 1,90 & 10 \\
\hline H. scomberoides & & & & & & & & 0 & 0,00 & & & 27 & 19 & 13 & 8 & 337 & 404 & 77,1 & 404 \\
\hline Total & 0 & 0 & 1 & 13 & 137 & 2 & 12 & 165 & 100 & 0 & 0 & 61 & 51 & 50 & 22 & 340 & 524 & 100 & 689 \\
\hline
\end{tabular}


FOLIA

H. scomberoides

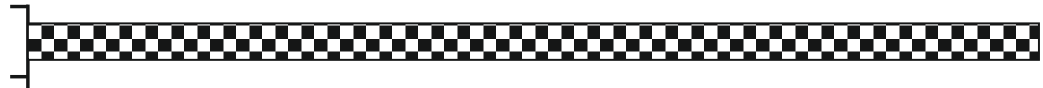

P. notatus

H. marginatus

P. flavipinnis

P. barbatus

B. platynemum

S. lima

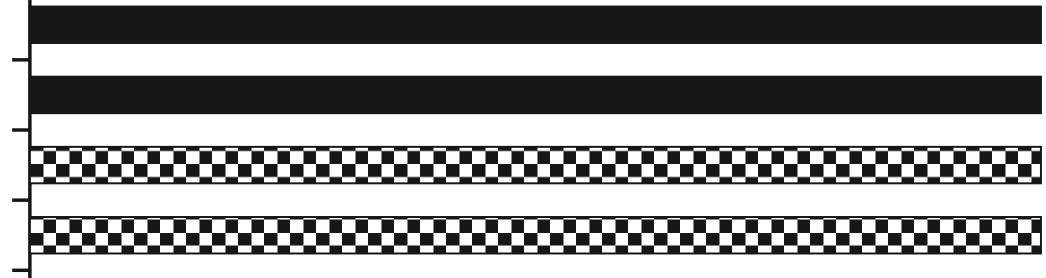

B. rousseauxii

B. filamentosum

L. marmoratus

A. nuchalis

P. blochii

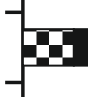

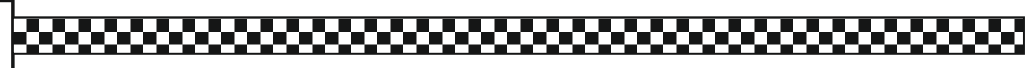

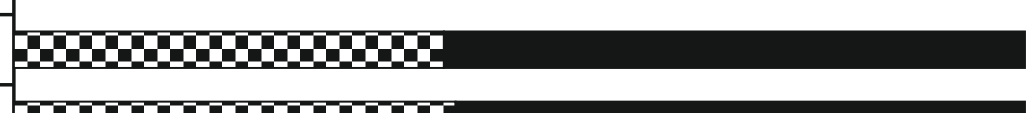

100000000000

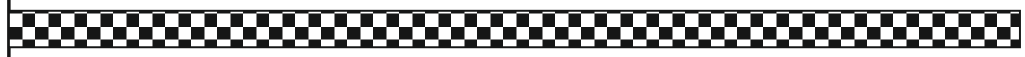

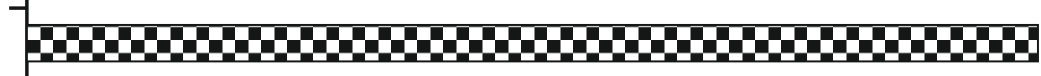

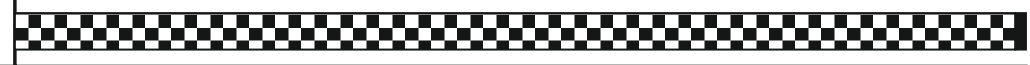

$0 \%$

$20 \%$

$40 \%$

$60 \%$

$80 \%$

$100 \%$

B creciente vaciante

Figura 4. Porcentaje de larvas por especie colectadas en los periodos hidrológicos de vaciante y creciente del 2012 en los ríos Arabela, Curaray y Napo. 


\section{DISCUSIÓN}

Las diferencias encontradas en la abundancia de larvas entre las estaciones de muestreo en las cuencas de los ríos Arabela, Curaray y Napo (Tabla 1), pueden ser explicadas por las diferentes épocas de reproducción entre especies analizadas y el tamaño y estabilidad de los cuerpos de agua de las cuencas evaluadas.

Las especies de peces identificadas entre las larvas analizadas en el presente estudio, están conformadas por medianos y grandes migradores, observándose una ausencia de especies no migratorias. Las migraciones son desplazamientos temporales y espaciales de toda o parte de la población de una especie entre dos sitios geográficos distintos, desplazamientos que son realizados para el mantenimiento de su ciclo de vida (Carolsfeld et al., 2003). Los peces se desplazan por tres causas principales: para reproducirse (desovar), para alimentarse o para buscar refugio. Peces como el dorado $B$. rousseauxii, el saltón $B$. filamentosum y tabla barba $B$. platymenum, identificados en este estudio, realizan migraciones reproductivas, desplazándose grandes distancias para desovar (Barthem y Goulding, 1997).

La ocurrencia diferencial de larvas entre los periodos hidrológicos según las especies, sugiere diferentes épocas de reproducción. La mayor parte $(>97 \%$ ) de las larvas de P. Blochii se encontraron en la época de creciente, infiriéndose un periodo de reproducción limitado a este periodo hidrológico. $\mathrm{La}$ reproducción durante el periodo de creciente, con un pico reproductivo en marzo, ya fue reportada para esta especie en la cuenca del río Madera por Barthem et al. (2014). Al contrario, el 100\% de las larvas de $H$. Scomberoides fueron encontradas en la época de vaciante, infiriéndose una reproducción exclusivamente para época de vaciante. Otro padrón observado fue el presentado por las especies de Brachyplatystoma, cuyas larvas fueron encontradas en ambos periodos hidrológicos, pero con mayor frecuencia durante la vaciante, correspondiendo, en la zona de estudio, a los meses de mayo a setiembre. Se confirma, por tanto, una época de reproducción preferencial para estas especies durante la época de vaciante, pero con una actividad residual para casi todo el año, como ya fue reportado con el análisis de reproducción de adultos en el alto Amazonas (García-Vásquez et al., 2009, Agudelo et al., 2013). Sin embargo, estos resultados contrastan con los estudios de larvas de pimelodidos en el Madera (basado en análisis morfológicos), quienes observan abundancia de larvas principalmente durante la creciente (Cañas y Pine 2010, Cañas y Waylen, 2011, Barthem et al., 2014).
Otro elemento a tener en cuenta en este análisis es el tamaño y la estabilidad de las cuencas evaluadas. El Arabela es un río pequeño de primer orden que no recorre grandes extensiones geográficas como los ríos Curaray y Napo, originados en los Andes. Por lo general, las especies migratorias se reproducen al pie de monte de los grandes ríos que transportan elevados volúmenes de agua y por ende, son más estables. Esto asegura, en el caso de algunas especies como el dorado $B$. rousseauxii y la tabla baba $B$. platinemum, que las larvas puedan ser arrastradas aguas abajo, hasta su destino final en la desembocadura del Amazonas en el Atlántico (Bathem y Goulding, 1997, 2007; Van Damme et al., 2011). Además, de esta forma evitan que sean desviados hacia zonas de inundación o várzeas, donde serían fácilmente depredados por otros peces (Araujo-Lima y Oliveira, 1998), pudiendo morir también por los bajos niveles de oxígeno disuelto durante el periodo de aguas bajas (Barthem y Goulding, 1997). En cambio, los ríos pequeños como el Arabela, son cuerpos de agua que tienen periodos de creciente y vaciante muy inestables, sujetos muchas veces a precipitaciones locales. Estos cuerpos de agua no solo transportan menores volúmenes de agua, sino también tienen un flujo reducido y niveles bajos de oxígeno, lo que podría causar mortandad en las larvas, principalmente en las de los bagres (Barthem y Goulding, 1997).

Otra característica no favorable para las especies que dependen de la deriva para distribuir los huevos y larvas, es que la posibilidad de llegar a un hábitat adecuado para el desarrollo juvenil, depende de factores medioambientales como el viento y la corriente, así como la relativa ubicación de los reproductores en relación con el movimiento de las masas de agua (Carvalho y Araujo-Lima, 2004). Si tenemos en cuenta además que las desembocaduras de los ríos de agua clara y ríos de agua negra son hábitats de flujo lento, donde el transporte pasivo de larvas se reduciría drásticamente, entonces la migración de adultos a ríos de agua blanca para desovar haría disminuir las pérdidas de embriones, debido al sedentarismo en hábitats de baja calidad, lo que resulta en un mayor éxito reproductivo (Carvalho y Araujo-Lima, 2004).

La presencia de larvas de bagres de valor económico como el dorado Brachiplatystoma rousseauxii, saltón $B$. filamentosum y tabla baba $B$. platynemum muestra la importancia de la cuenca del río Napo en el mantenimiento del ciclo de vida de estos grandes bagres.

En conclusión, la Información generada puede servir de base para el establecimiento de estrategias 
para la conservación y gestión de estas especies en esta parte de la cuenca del Amazonas, zona en la que se han incrementado los impactos derivados de las actividades económicas y demográficas de la creciente ocupación de la Amazonia, como son la sobre pesca, destrucción de hábitats, contaminación y construcción de represas.

Tienen que implementarse una serie de medidas de mitigación o prevención para salvaguardar estos recursos pesqueros en esta área de la Amazonía, más aún ahora que el gobierno está planificando la construcción de una represa hidroeléctrica en esta cuenca, por lo que recomendamos se considere la construcción de vías de translocación especiales para peces migratorios, que permitan la migración aguas arriba de estos grandes bagres. Estudios recientemente publicados muestran que en el río Madera, las vías de translocación de las hidroeléctricas el Jirau y Santo Antonio (recientemente construidas en la Amazonia brasilera), no son funcionales para los bagres como el dorado, causando una ruptura en los ciclos de migración de los grandes bagres en esta región (Carvajal-Vallejos et al., 2014). Por lo que los megaproyectos tienen que considerar medidas efectivas para el mantenimiento del ciclo de vida de estos stocks pesqueros, lo que evitará que a la larga se produzcan no solo pérdidas económicas, sino también escasez de fuentes de proteína animal para los pobladores de esta región.

\section{AGRADECIMIENTO}

Los autores agradecen a la empresa PERENCO PERU PETROLEUM LIMITED por el financiamiento del presente estudio, a través del proyecto "Evaluación hidrobiológica de los ríos Arabela y Curaray (cuenca del río Napo)".

\section{BIBLIOGRAFÍA CITADA}

Agudelo, E.; León, Á.V.J.; Bonilla-Castillo, A.; Petrere Jr, M.; Peláez, M.; Duponchelle, F. 2013. Breeding, growth and exploitation of Brachyplatystoma rousseauxii in the Caqueta River, Colombia. Neotropical Ichthyology, 11:637-647.

Aquilino, S.; Tango, J.; Fontanilla, I.; Pagulayan, R.; Basiao, Z.; Ong, P.; Quilang, P. 2011. DNAbarcoding of the ichthyofauna of Taal Lake, Philippines. Molecular Ecology Resources, 11: 612-619.

Araújo-Lima, C.A.R.M.; Donald, E. 1988. Número de Vértebras de Characiformes do río Amazonas e seu uso na identificação da larvas do grupo. Acta Amazonica, 18(1-2): 351-358.
Araujo-Lima, C. A. R. M., and E. C. Oliveira. 1998. Transport of larval fish in the Amazon. Journal of Fish Biology, 53:297-306.

Ardura, A.; Pola, I. G; Ginuino, I.; Gomes, V.; García-Vásquez, E.; 2010. Application of barcoding to Amazonian commercial fish labeling. Food Research International, 43: 1549-1552.

Asgharian, H.; sahafi, H.H.; Ardalan, A.A.; Shekarriz, S.; Elahi, E. 2011. Cytochrome c oxidase subunit I barcode data of fish of the Nayband National Park in the Persian Gulf and analysis using meta-data flag several cryptic species. Molecular Ecology Resources, 11: 461-472.

Barthem, R.B.; Goulding, M. 1997. The catfish connection. Biology and Resource Management in the Tropics Series. Columbia University Press. New York. 145pp.

Barthem, R.B.; Goulding, M. 2007. Un ecosistema inesperado: A Amazonia revelada pela Pesca. Grafica Biblos, Lima-Perú, 241pp.

Barthem, R.; da Costa, M.C.; Cassemiro, F.; Leite, R.G.; Silva Jr. N. 2014. Diversity and Abundance of Fish Larvae Drifting in the Madeira River, Amazon Basin: Sampling Methods Comparison. In: Grillo, O (Ed.). Biodiversity - The Dynamic Balance of the Planet InTech.p. 137-158.

(http://www.intechopen.com/books/biodiversit y-the-dynamic-balance-of-the-planet/diversityand-abundance-of-fish-larvae-drifting-in-themadeira-river-amazon-basin-samplingmethods-c.) Acceso: 20/05/2014.

Cañas, C. M.; Pine, W.E. 2010. Documentation of the temporal and spatial patterns of pimelodidae catfish spawning and larvae dispersion in the Madre de Dios River (Peru): Insights for conservation in the Andean-Amazon headwaters. River Research and Applications, 27(5): 602-611. doi: 10.1002/rra.1377

Cañas, C. M.; Waylen, P.R. 2011. Modelling production of migratory catfish larvae (Pimelodidae) on the basis of regional hydroclimatology features of the Madre de Dios Basin in southeastern Peru. Hydrological Processes, 26(7): 996-107. doi: 10.1002/hyp.8192

Carolsfeld, J.; Harvey, B.; Ross, C.; Baer, A. editors. 2003. Migratory fishes of South America: Biology, Fisheries and Conservation status. IDRC, World Bank, Washington, USA (http://books.google.com.pe/books?id= GCF3 kK6_8cC\&printsec $=$ frontcover\&source $=\mathrm{gbs} \_\overline{\mathrm{g}}$ e_summary_r\&cad $=0 \# \mathrm{v}=$ onepage $\& \mathrm{q} \& \mathrm{f}=$ false) Acceso: 20/02/2013 
Carvajal-Vallejos, F.M.; Duponchelle, F.; Desmarais, E.; Cerqueira, F. Querouil, S.; Núñez, J.; García-Dávila, C.; Renno J.-F. 2014. Genetic structure in the Amazonian catfish Brachyplatystoma rousseauxii: influence of life history strategies. Genetica, 142(4): 323-36. doi: 10.1007/s10709-014-9777-2.

Carvalho de Lima, A.; Araujo-Lima, C.A.R.M. 2004. The distributions of larval and juvenile fishes in Amazonian rivers of different nutrient status. Freshwater Biology 49:787-800.

Doyle, J. J.; Doyle J. L. 1987. A rapid DNA isolation procedure for small quantities of fresh leaf tissue. Phytochemical Bulletin, 19:11-15.

Galvis, G.; Mojica, J. I.; Duque, S.; Castellanos, C.; Sánchez, P.; Arce, M.; Gutiérrez, A.; Jiménez, L.; Santos M.; Vejarano, S.; Arbeláez, F.; Prieto, E.; Leiva, M. 2006. Peces del medio Amazonas, Región de Leticia - Conservación Internacional, Colombia. $546 \mathrm{pp}$

García-Dávila, C.; Chota-Macuyama, W.; CastroRuiz, D.; Vasquez, G.; Corazón-Guivin, M.; García, J.; Carvajal-Vallejos, F.; Sánchez, H.; Duponchelle, F.; Núñez, J.; Chu-Koo, F.; Renno, J-F. 2009. Avances del uso del "Barcoding" en la identificación de larvas de bagres (Siluriformes) en la Amazonia peruana. In: J. Núñez, F. ChuKoo, J. Porto, C. García-Dávila (Eds.), Biología de las poblaciones de peces de la Amazonía y Piscicultura. 59-69 p.

García Vásquez, A.; Alonso, J.-C.; Carvajal, F.; Moreau, J.; Nunez, J.; Renno, J.-F.; Tello, S.; Montreuil, V.; Duponchell, F. 2009. Life-history characteristics of the large Amazonian migratory catfish Brachyplatystoma rousseauxii in the Iquitos region, Peru. Journal of Fish Biology, 75: 2527-2551.

Habit, E.; Victoriano, P.; Rodríguez-Ruiz, A. 2003. Variaciones espacio-temporales del ensamble de peces de un sistema fluvial de bajo orden del centro-sur de Chile. Revista chilena de historia Natural, 76:3-14.

Hall, T. A. 1999. BIOEDIT a user - friendly biological sequence aligment editor and analysis program for Windows 95/98/NT. Departament of Microbiology North Carolina State University. Nucleid Acids Symposium Series, 41: 95-98.

Hebert, P.D.N; Penton, E.H.; Burns, J.M.; Janzen, D.H.; Hallwachs, W. 2004a. Ten species in one: DNA barcoding reveals cryptic species in the neotropical skipper butterfly Astraptes fulgerator. Proceedings of the National Academy of Sciences USA, 101: 14812-14817.
Hebert, P.D.N.; Stoeckle, M.Y.; Zemlak, T.S.; Francis, C.M. 2004b. Identification of birds through DNA barcodes. Public Library of Science, 2: 1657-1663.

Hubert,N.; Hanner, R.; Holm, E.; Mandrak, N.E.; Taylor, E.; Burridge, M.; Watkinson, D.; Dumont, P.; Curry, A.; Bentzen, P.; Zhang, J.; April, J.; Bernatchez, L. 2008. Identifying Canadian Freshwater Fishes through DNA Barcodes PloS One 3: e2490.

Kurtz, J.C.; Jackson, L.E.; Fisher, W.S. 2001. Strategies for evaluating indicators based on guidelines from the Evironmental Protection Agency's Office of Reasearch and Development. Ecological Indicators, 1:49-60.

Lakra, W. S.; Verma, M. S.; Goswami, M.; Lal, K. K.; Mohindra, V.; Punia, P.; Gopalakrishnan, A.; Singh, K. V.; Ward, R. D. Hebert, P. 2011. DNA barcoding Indian marine fishes. Molecular Ecology Resources, 11: 60-71.

Leite, R. G., Silva, J. V., Freitas, C. E. 2006. Abundância e distribuição das larvas de peixes no Lago Catalão e no encontro dos rios Solimões e Negro, Amazonas. Acta Amazonica, 36(4): 557-562.

Leite, R. G., Cañas, C., Forsberg, B., Barthem, R., Goulding, M. 2007. Larvas dos Grandes Bagres Migradores. Instituto Nacional da Pesquisas da Amazônia (INPA)/Asociación para la Conservación de la cuenca Amazónica (ACCA). Primera Edición. Manaus-Brasil. 127pp.

Mojica, J.I.; Usma, J.; Álvarez, R.; Lasso, C. 2012. Libro Rojo de peces dulceacuícolas de Colombia. Instituto de Investigaciones de recursos Hidrobiologicos Alexander von Humboldt. Colombia, 319pp.

Nakatani, E., A. Agostinho, G. Baumgartner, A. Bialetzki; P. Vanderlei, M. Cavicchioli, C. Simone. 2001. Ovos e larvas de peixes de água doce, desenvolvimento e manual de identificação. Editora da Universidade Estadual de Maringá, Brasil. 378p.

Ortega, H.; Chocano, L.; Palma, C.; Samanez, I. 2010. Biota acuática en la Amazonía peruana: diversidad y usos como indicadores ambientales em el bajo Urubamba (Cuzco-Ucayali). Revista Peruana de Biología, 17(1):029-035.

Paradis, E.; Claude, J.; Strimmer, K. 2004. APE: Analyses of phylogenetics and evolution in $\mathrm{R}$ language. Bioinformatics, 20: 289-290

Reis, R. E., Kullander, S. O. y Ferraris, C. J. 2004. Checklist of Freshwater Fishes of South and Central America. Porto Alegre: Edipucrs. 
Steinke, D.; Zemlak, T. S.; Hebert, P.D.N. 2009. Barcoding Nemo: DNA-Based Identifications for the Ornamental Fish Trade. PloS One, 4: e6300

Tamura, K.; Dudley, J.; Nei, M.; Kumar, S. 2007. MEGA versión 4.0: Molecular Evolutionary Genetics Analysis (MEGA). Molecular Biology and Evolution, 24: 1596-1599

Thompson, J.D.; Higgins, D.G.; Gibson, T.J. 1994 CLUSTAL W: improving the sensitivity of progressive multiple sequence alignment through sequence weighting, position- specific gap penalties and weight matrix choice. Nucleic Acids Res., 22: 4673-4680.

Van Damme, P.; Carvajal-Vallejos, F.; MolinaCarpio, J. (eds.) 2011. Los peces y delfines de la Amazonía boliviana: Habitats, potencialidades y Amenazas. Editorial INIA, Cochabamba, Bolivia, 490pp.
Wong, L.L.; Peatman, E.; Lu, J.; Kucuktas, H.; He S.; Zhou, C.; Na-nakorn, U.; Lui, Z. 2011. DNA Barcoding of Catfish: Species Authentication and Phylogenetic Assessment. PLoS One 6(3): e17812.

Zhang, J.B.; Hanner, R. 2011. DNA barcoding is a useful tool for the identification of marine fishes from Japan. Biochemical Systematics and Ecology, 39: 31-42.

Recibido: 09/01/2014

Aceptado para publicación: 27/03/2014 